Murphy, Z., Saripally, D., Dhakla, S., Trujillo, R., Luttmann, E. and Sreekumar, A. (2018). "Leveraging Advanced VDC Methods and Reality Capture to Increase the Predictability for Prefabrication" In: Proc. $26^{\text {th }}$ Annual Conference of the International. Group for Lean Construction (IGLC), González, V.A. (ed.), Chennai, India, pp. 101-111. DOI: doi.org/10.24928/2018/0443. Available at: www.iglc.net.

\title{
LEVERAGING ADVANCED VDC METHODS AND REALITY CAPTURE TO INCREASE THE PREDICTABILITY FOR PREFABRICATION
}

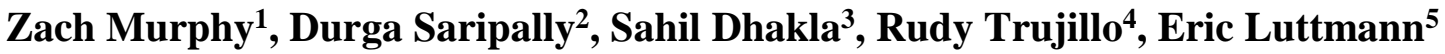 \\ and Aiswarya Sreekumar 6
}

\begin{abstract}
Construction processes happen in partially controlled environment; resulting in prefabricated components being vulnerable to variances resulting from deviation in quality of work put in place. However, wider adoption of VDC methods and advances in Reality Capture technology has opened up avenues for adopting prefabrication in construction projects by enhancing predictability using two methodologies. First, the use of advanced VDC methods to create highly detailed and coordinated models. Second, incorporating deviations in installed/existing building components using as-built 3D models created from laser scans of the construction site.

This paper focuses on case studies of commercial projects in the USA that have prefabricated interior wall partitions, resulting in higher productivity and quality. Further, it would outline the processes and workflows used by a global team, located in the USA and India; concluding with quantitative and qualitative benefits observed on these projects.
\end{abstract}

\section{KEYWORDS}

Lean Construction, Prefabrication, Reality Capture, VDC, digital fabrication, assembly

1 Director, v Construct Private Limited, Pune, India, +1 - 6504741450, ZachM@dpr.com

2 Operations Manager, vConstruct Private Limited, Pune, India, +91- 8446001611, durgas@vconstruct.in

3 Project Engineer, v Construct Private Limited, Pune, India, +91- 9464955401, sahild@ vconstruct.in

4 Design Manager, Digital Building Components, Phoenix, Arizona, +1- 6023294255, rudyt@digitalbuilding.com

5 BIM Project Engineer, Digital Building Components, Phoenix, Arizona, +1- 2159138611, ericlu@digitalbuilding.com

6 Sr. Project Engineer, v Construct Private Limited, Pune, India, +91- 8826367246, aiswaryas@vconstruct.in 


\section{INTRODUCTION}

Construction projects are nonstandard, unique, single-order and single production products (Arditi and Gunaydin 1997). Unlike manufacturing and other productions, which have fixed site and similar production conditions, construction production sites always display non-standard site conditions and installations. Consequently, due to nonrepeating activities, lack of clarity and non-uniform standards, variations occur in the quality of work in-place. In current practices, the subsequent trade activities adjust and absorb variations. This limits the scope of prefabrication in construction projects. When construction defects are detected later during prefabricated trade installation, they can have cost implication in the form of rework on site and delays.(Vishal et al. 2015) This causes quality concerns when prefabricated elements must be assembled in place on site.

However, wider and deeper implementation of VDC methods allows to leverage the technology to prefabricate different building elements. This work attempts to showcase an approach for detecting and enhancing predictability for variances and accommodation for tolerances on site. This approach can help to capture such deviations early in the construction process for subsequent prefabricated element installations. This is needed since such defects eat into the overall savings made by general contractors and small trade contractors. This could be because of the rework on prefabricated elements which are unforeseen prior to shipping and installation, due to on site variances caused by defects.(Arditi and Gunaydin 1997)

Previous studies of BIM and Lean have explained BIM enabled automated work package creation, resource levelling, value planning, prefabrication, and benefits of coordination through the use of BIM.(Gerber et al. 2010), RFI associated with interface between architecture and structure of a BIM model (Filho et al. 2016), real time supply chain management using VDC and Lean (Cho and Fischer 2010), etc. This paper builds on the findings of the above-mentioned research. In addition, it also delves in the benefits of using Reality Capture techniques in construction projects. Use of reality capture as feedback for prefabricated wall panels is based on the lean theory of continuous improvement. It allows for feedback from site for accurate design of prefabricated elements. The identification and avoidance of risk for prefabricated wall panels during the construction lifecycle is possible by using advanced VDC methods and reality capture. This approach has not been captured in previous studies.

At present there is limited active construction quality predictability approaches being leveraged for prefabrication. The quality of work put in place on the site is subject to a larger tolerance than most activities that are machine controlled. Current surveying and quality checks are not effective. They only provide data at specific location and time to represent work in place. Such data are interpreted manually and are not integrated electronically into project design model and prefabrication spooling information set. However, in digital fabrication, robotic welders use laser for accurate placement - straight from MWF model. Robot welds at $+/-1 / 8$ " tolerance for placements taking accurate data from model. 


\section{BACKGROUND RESEARCH}

\section{OVERVIEW OF THE APPROACH}

The study identifies the problems which lead to waste during construction relating to the prefabricated elements -

- waiting: for preparation of element which doesn't have enough clearance, or needs to be provided opening/beam pocket etc. in the prefabricated panel or for chipping of nearby structural element

- defect: in vicinity of location of installation of prefabricated element

And demonstrates solutions using case study to implement lean philosophy with the help of advanced VDC methods and Reality capture. The different approaches are practically implemented in the cases mentioned here, at different stages of the project.

The context of this study is defined by 2 case projects based in the USA, carried out by company $\mathrm{P}$ (general contractor) having extensively defined usage of BIM services under the standard services contract with company V, based in India. Project $\mathrm{G}$ is a tenant improvement effort for a commercial development in high-tech business park located in Bay Area, USA. Project M is tenant improvement effort for a pharmaceutical research laboratory building in Bay Area, USA. Company D is drywall contractor for both projects.

Finally, the study focuses to evaluate the optimization possible by following these approaches. Personal interviews have been conducted with personnel from project team representing company $\mathrm{P} \&$ company $\mathrm{D}$. The series of questionnaire administered helped to validate the approach conceptualized through the course of the projects demonstrated here via case studies.

\section{PREFABRICATED PANEL MANUFACTURING - COMPANY D WORKFLOW}

Construction of interior walls using light-gauge metal-stud framed walls requires coordination with multiple trades. Construction of metal stud walls happens in three phases that are interspersed by activities of other trades-layout of top track, installation of stud framing, and gypsum board sheathing \& finishing. Company D manufactures wall panels, complete with framing for MEP openings, using computer numerical control (CNC) machine based on 3D models developed by company V. The Revit-based 3D models incorporate site constructability considerations and are also coordinated with other building systems (Figure 1). In addition to the elements required for coordination, the model also incorporates location of punches and welds to inform the $\mathrm{CNC}$ machine. 


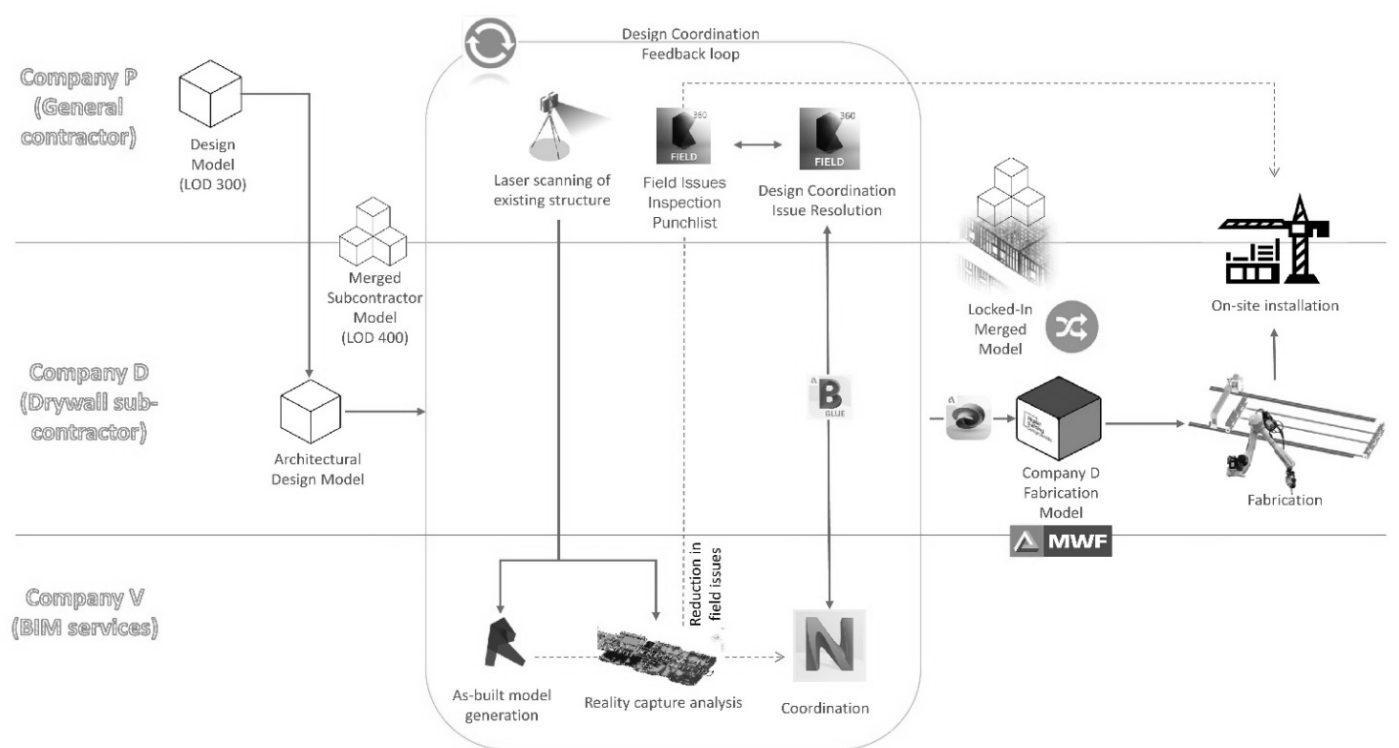

Figure 1: Design coordination feedback loop workflow

\section{VDC METHODS TO ENHANCE PREDICTABILITY MODELLING FOR FABRICATION}

Currently, the design of prefabricated wall panels is done by using the $2 \mathrm{D}$ buildout plans $\&$ architectural 3D design model as reference. The 2D buildout plans highlight the location of wall panels. However, the 3D model allows to check for constructability \& model integrity.

Firstly, a stripped architectural model is generated. Company V creates a basic architectural model in Revit, using 2D design drawings, that contains walls, doors, windows and other relevant elements. The walls are then broken into smaller parts that represent individual wall panels. Using a Revit based plugin, the framing is generated as per design and construction guidelines.

\section{INCREASING PREDICTABILITY - BIM COORDINATION}

The drywall framing model is checked for clashes with other systems like HVAC ducting, plumbing and fire protection lines in a federated model. Once the layout of all the systems is finalized after resolution of all clashes, the signed-off models are used to adjust the framing of openings in the drywall model.

This is different from the traditional construction process where MEP openings are framed on site on basis of MEP already installed. It also requires that installation of all systems happen as per the sign-off model. The pre-planning results in a cost savings, better flow of work and faster installation.

\section{ENHANCING PREDICTABILITY - REALITY CAPTURE}

Recent development in prefabricated wall panel design process is to bring the feedback for site conditions by using reality capture. The laser scanning of the facility which is 
under construction allows the possibility of analysing the variation in building components which could be affecting the clearances for the installation of prefabricated elements.

These variations occur due to deviations which evolve while the construction happens on site. For instance, the deviation in floor flatness during the concrete casting. Using traditional VDC method, the height of wall panel which is to be fabricated can be found out by using design model. Whereas, due to deviation of site conditions from design conditions generally, the available clearance height could be varying. Magnitude of this variation depends on the quality check and compliance followed while construction is executed. These variations can be considered by using the construction site point cloud data as reference while generating the 3D model for wall panel prefabrication.

The 3D model generated using this approach considers the on-site variations and helps the prefabrication team to generate accurate height wall panels. The "accurate to site condition" wall panel output is generated from 3D model and used as input for prefabrication in CNC machine. This process removes the possibility of rework and material wastage which occur when the wall panels would not fit in place during installation due to variation in available clearance on-site.

The point cloud data captures site conditions with up to $3 \mathrm{~mm}$ accuracy. This allows analysis of the relevant components present on-site which pose risk for installation of prefabricated elements. This risk could be either material wastage or rework to fix the wall panel or the component which clashes with it.

\section{ENHANCING PREDICTABILITY - ADVANCED VISUALIZATION AND PLANNING}

Advanced visualisation and planning creates benefits for the project in terms of time and cost saving by avoiding unnecessary on-site installation and coordination efforts for different services. The services can be checked for routing and constructability issues before actual installation on site.

The virtual design construction provides a platform for collaborating in the 3D model environment, the different systems which are to be built or are already present on site before construction. The analysis of the 3D model for various purposes such as coordination, constructability check, model integrity check etc. provides enhanced predictability for components which must be engineered to order.(Tillmann et al. 2015)

Using digital fabrication, the involvement of robots and 3D model provides better predictability and quality assurance. Predictability is enhanced due to usage of 3D visual models and lesser manual intervention.

\section{CASE STUDIES}

The drywall subcontractor, company D, executed wall panel fit-out job for project $\mathrm{G} \&$ project M. Drywall installation effort for Project G was carried out precedent to project M. 
There were few coordination and constructability issues faced by team during project G. Such as, some panels could not be installed on-site since they were not coordinated with the accurate as-built core \& shell structure. Also, panels were not coordinated with MEP trades from sequencing standpoint. This lack of sequencing communication led to delay in panel installation. This was because, the MEP trade subcontractor had to remove their elements while drywall subcontractor waited. At few locations, MEP trades could not remove runs and multiple wall panels were re-fabricated with modification or were adjusted manually on-site while doing installation effort.

In project $\mathrm{G}$, structural model based on record drawing did not accurately reflect the site conditions. To update the structural and fire protection pipes model as per as-built conditions, a detailed QC was done using point cloud data as reference. The deviations were captured in the modified as-built model. This accurate as-built model was then used for coordination of all subsequent trades.

Company $\mathrm{P}$ site team was provided with a heat map (Figure 2) showing the 2D graphic representation of the variation in floor height. The floor slope analysis was done before arriving at site, so that the team could plan for fixing potential issues which would affect the wall panel installation. The upfront effort streamlined panel installation. Further, no effort was spent onsite in changing the panels to site conditions. The team identified areas where floor is to be chipped/grouted or filled for creating levelled surface. A dedicated team worked on surface preparation using heat map before wall panel fixing team started panel installation effort. This allows to streamline the process of installation of prefabricated dry wall panels, avoiding rework and material wastage.

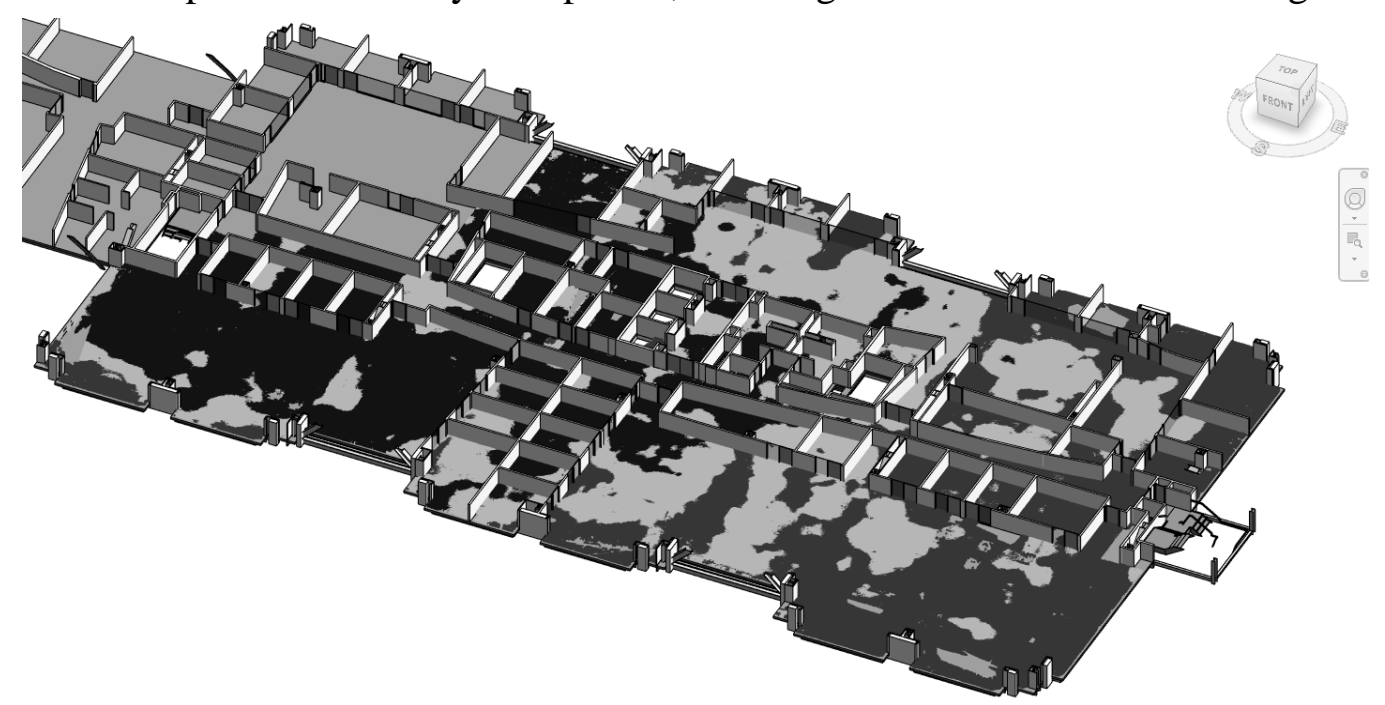

Figure 2: Heat map generated from point cloud data referenced on the wall panel design model

Also, a floor 3D model was developed in Revit from point cloud data, which reflected actual site conditions. The floor model with $1 / 8^{\text {th }}$ in. accuracy was created using automated process to pick the available point cloud data. This 3D as-built floor model was clash-coordinated with the wall panel 3D model in Autodesk Navisworks to identify 
places having insufficient clearance causing potential issue of material wastage or rework on site. The clash report was generated to identify major clashes, using which adjustment were done in wall panel design model and notified to team working on site for installation effort. (Figure 3)

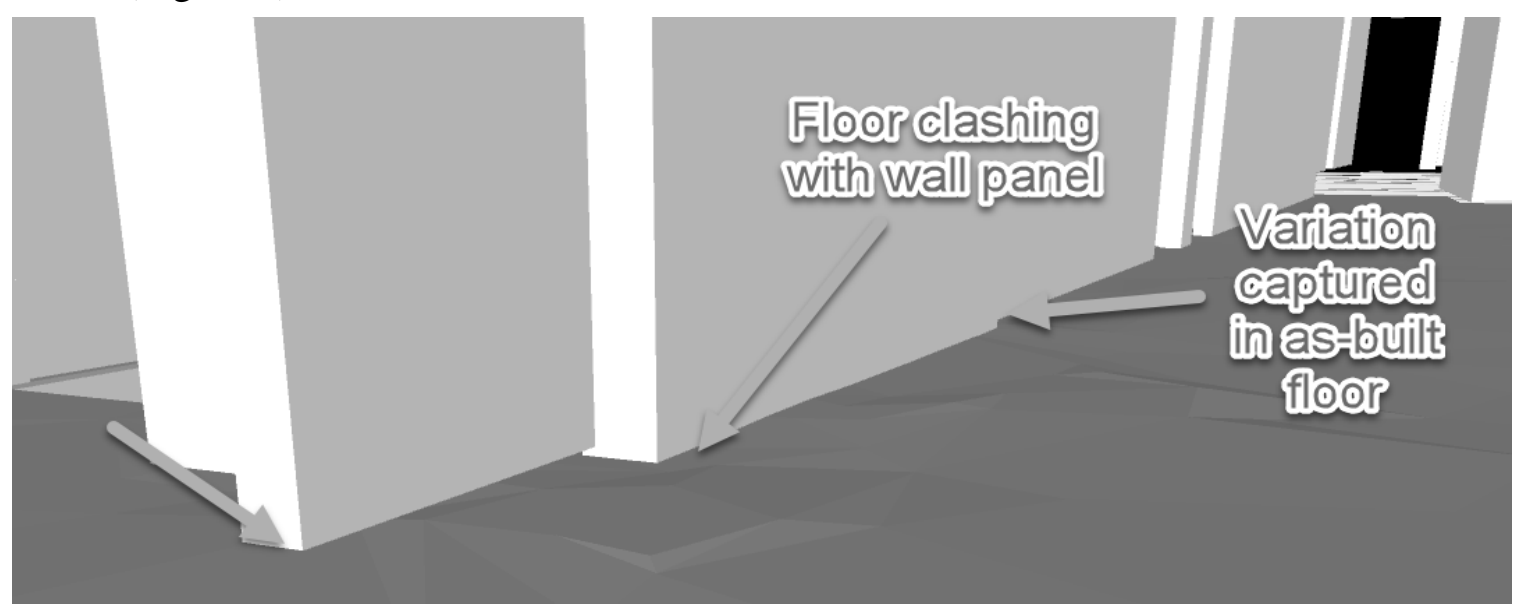

Figure 3: As built floor clash check with wall panels

Evolving the workflow along the course of these projects, during the prefabricated wall panel designing process for project $\mathrm{M}$, the drywall modelling team utilized coordination and reality capture feedback loop during the wall panel designing phase. The cut-outs and openings were coordinated in the wall panel for fabrication model. The panel was fabricated with the MEP openings in the panel. This allowed transferring of on-site efforts to factory conditions. (Figure 4)

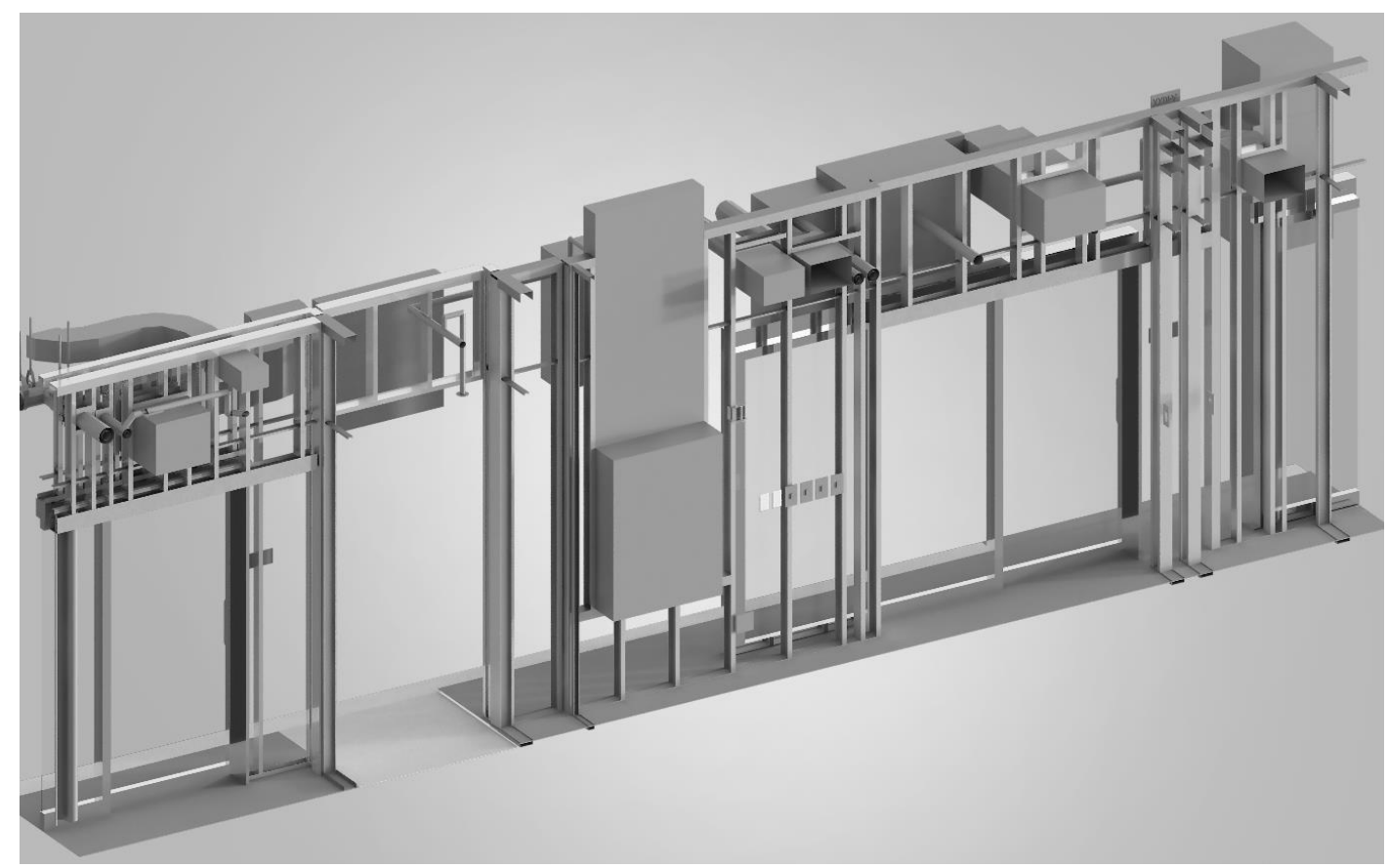

Figure 4: MEP openings coordinated with drywall panels 
Further, the team identified clearance available accounting for deflection and as-built layout of the deck above for every wall location. This analysis used the laser scan of the space after concrete was poured on the deck above. Since the wall panels were full height (up to deck level), the coordination with flutes was necessary. The location of crest and troughs for flutes is captured in the point cloud data. The point cloud data is aligned with the 3D stripped architectural model for analysis of existing conditions while designing wall panels. The height for wall panels is adjusted to match the top track with trough of the fluted deck (Figure 5). The kickers/posts for supporting the wall panels are also adjusted to align with the fluted deck. The spacing of top track hole series is generated by referring the distance between the flutes $(\sim 6$ "), using the point cloud data (Figure 6).

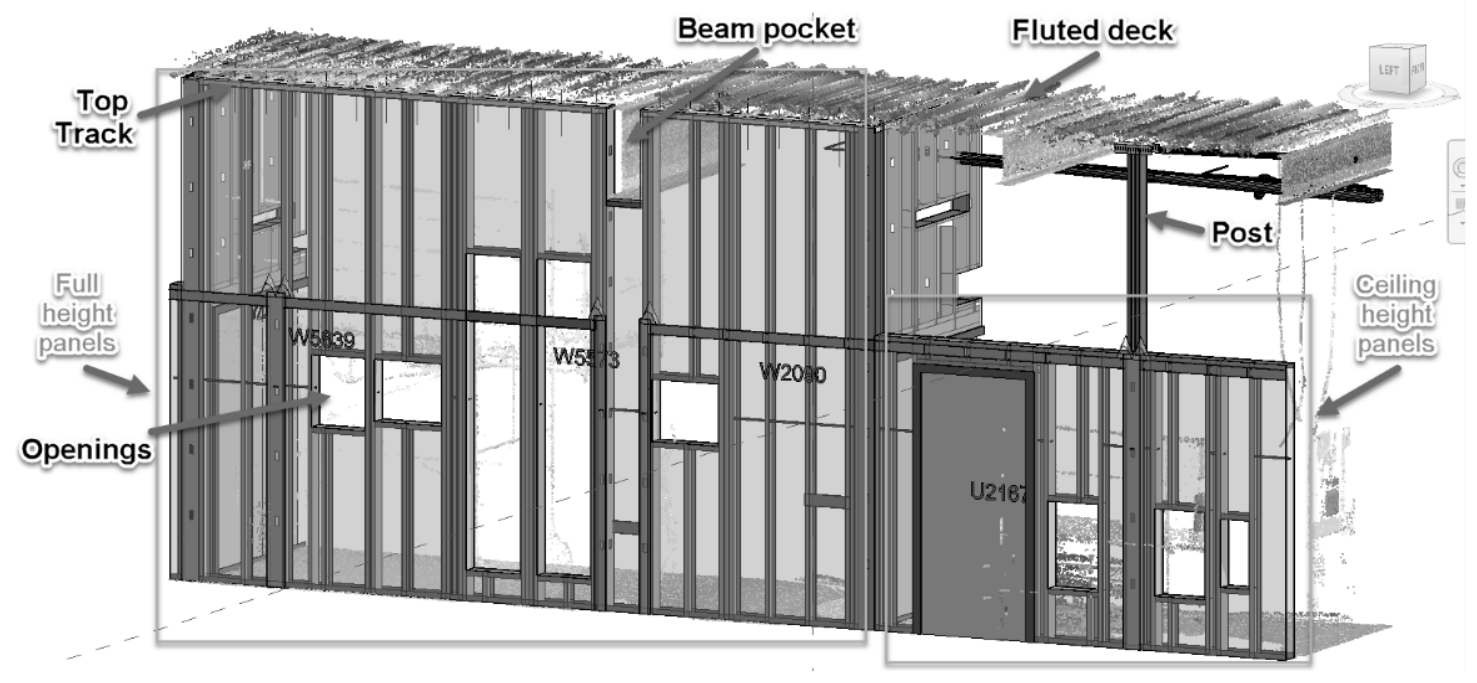

Figure 5: Point cloud data referenced on the wall panel design model

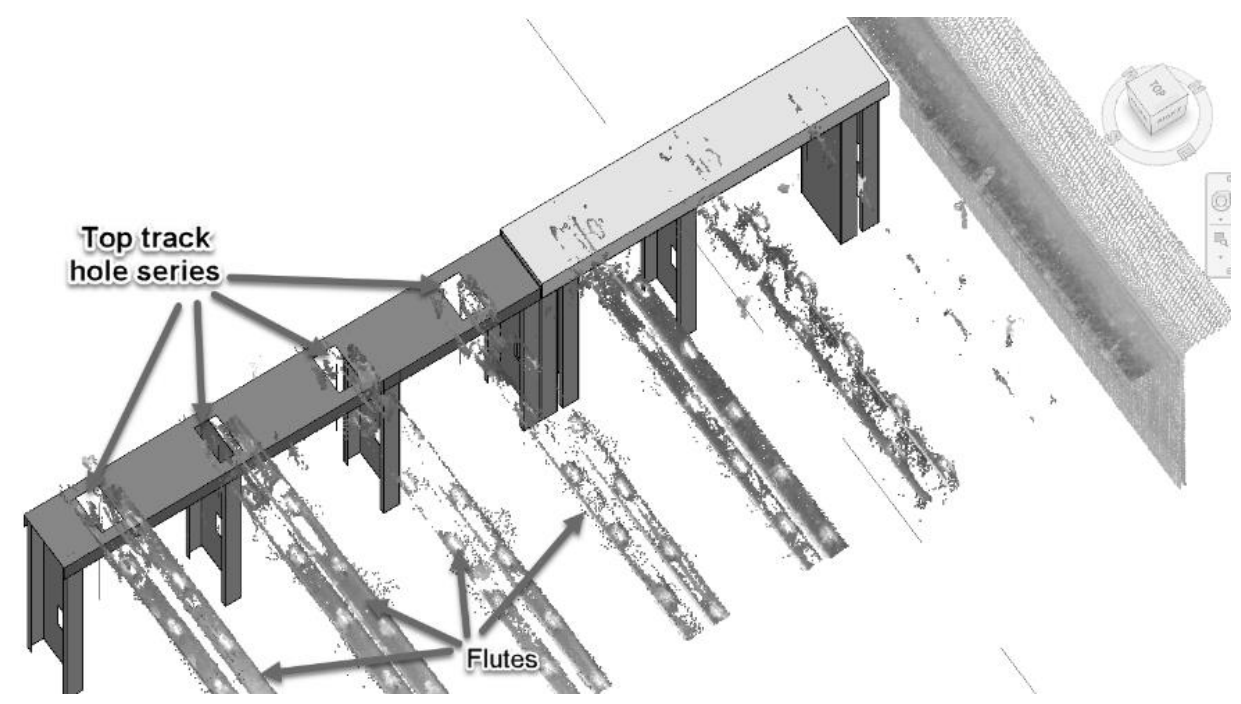

Figure 6: Top track hole series punched referring to flute locations in laser scan 
A report was generated following this workflow, which shows the adjustment in height with $1 / 8^{\text {th }}$ inch accuracy for individual wall panel. For 9 levels, each having around 100-110 wall panels, the adjustment was reported for $60-70 \%$ panels (Figure 7). The report was then used to alter the parameters for fabrication.

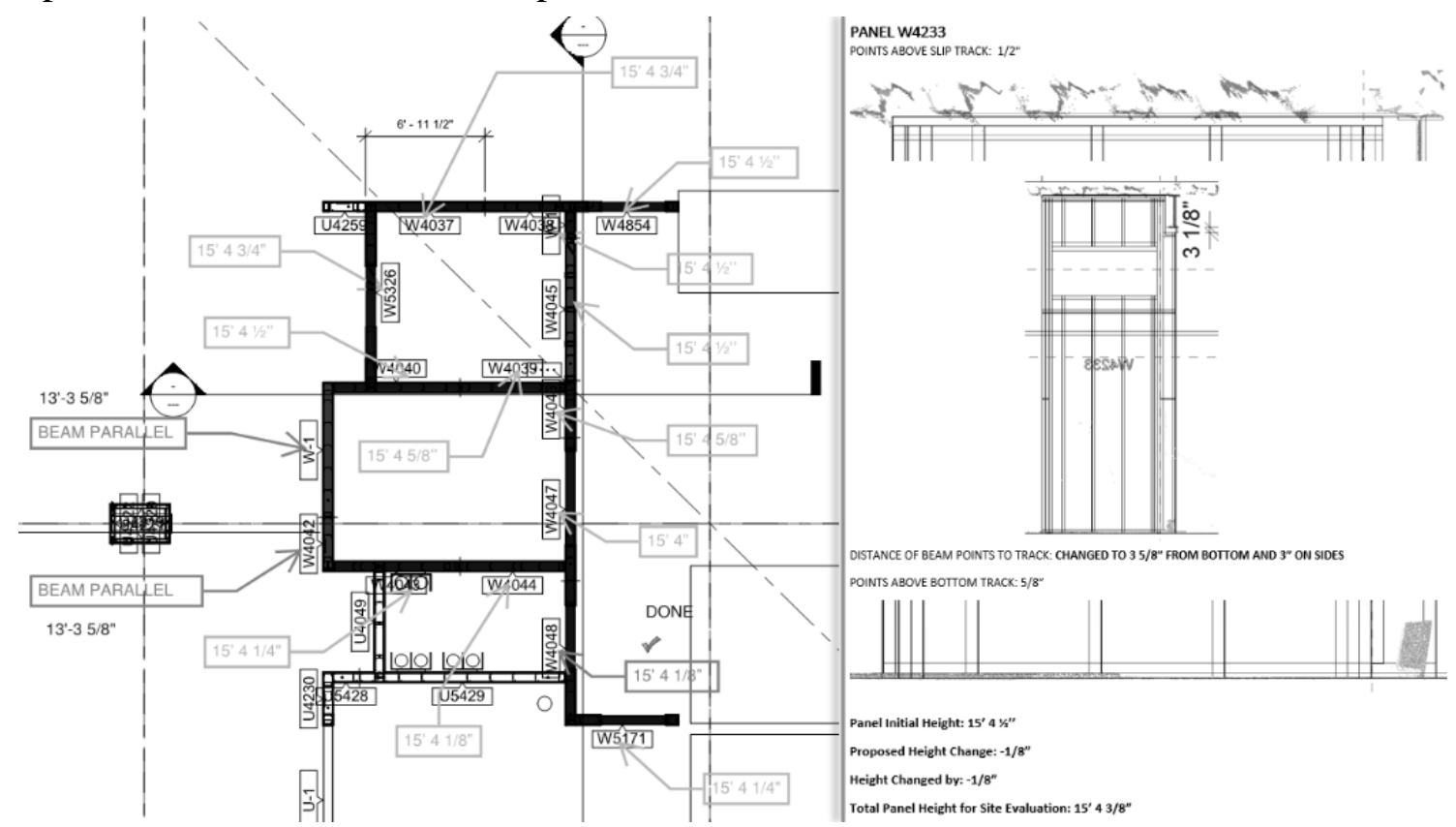

Figure 7: Wall panel adjustment report

\section{CHALLENGES, LIMITATIONS \& SUCCESS}

The timeframe for laser scanning the site and for incorporating the as-built conditions in the design model is critical because of constraints in the schedule and timeline for BIM execution. The drywall subcontractor has reported multiple instances where wall panel clashed with beam/column onsite as the steel model used for coordination was not detailed out or updated. It is essential that the level of detailing required of interfacing systems modelled by other subcontractors is identified early on and incorporated in BIM Implementation Plan and in buy-out.

The adjustments made to sub-contractor's model after coordination causes clashes in a prefab panel. In on-site drywall construction, such adjustments would be made in the field; possibly at loss of productivity for one or both crews. It is imperative that a communication protocol is established to communicate changed made after coordination sign-off. Additionally, VDC methods can be employed to detect incremental changes in the model.

A further challenge is posed by the deviations that happen on the site during installation. Laser Scanning provides the most accurate way to capture field changes. Some of the challenges associated with laser scanning follow.

Laser scanning process is time and money consuming effort and therefore should be planned properly (Gleason 2013). There is requirement for high-end processing computer 
systems to deal with the point cloud data. The scan alignment to model is a factor which plays important role in defining overall accuracy of process. Overlaying point cloud data and 3D model is possible only if both model and point cloud are using same coordinates. But generally, laser scanning is done without geo-referencing. Therefore, the scan is not referenced at the coordinates of design model. Therefore, we need to align the point cloud to 3D model using best-fit approach (Murphy et al. 2009). This is a limitation of using the reality capture approach for feedback from site, especially in situations where the tolerances are less than one-quarter inch.

In both the case studies, the team has been working on providing better and more usable information using VDC methods. The use of reality capture feedback addresses field deviations efficiently. Further automation and streamlining of certain processes will enable wider implementation of these methods. Further study needs to be done to arrive at statistically relevant metrics. However, we may conclude that the impacts of deploying VDC and Reality Capture in prefabrication results in streamlining flow and provide better quality of work.

\section{CONCLUSION AND FUTURE WORK}

Using VDC methods increases the predictability and provides feedback loop. Modelling using BIM allows digital fabrication. Using this approach company D claims high productivity (25-30\% faster erection/installation schedule) without mass production and lesser labour involvement. For full height interior framing, installation productivity being 100 linear feet/person/day in current technique vs 25 linear feet/person/day in traditional method. Coordination of different trades allows predictability. Additionally, in the second case, it has been demonstrated how reality capture provides feedback in design phase to create accurate model for digital fabrication of building components.

The approach of using heat \& contour maps helped to avoid waiting period in the process of wall panel installation. The identification of defects helps the team to strategize the execution process.

The usage of heat \& contour map is during the execution phase, whereas the 3D asbuilt floor model can be utilized in design coordination phase. The extraction of as-built floor/roof model from point cloud using Dynamo renders to a highly detailed as-built model which may not be always useful considering the lag in operating the model while designing. The optimisation of this output is being researched for better utilisation in above mentioned workflow.

\section{ACKNOWLEDGEMENT}

The personnel from the stakeholder companies, who contributed to the research have shown tremendous interest and willingness to participate and authenticate this study. Also, the BIM team from all stakeholders have been crucial in the success of this paper. 


\section{APPENDIX}

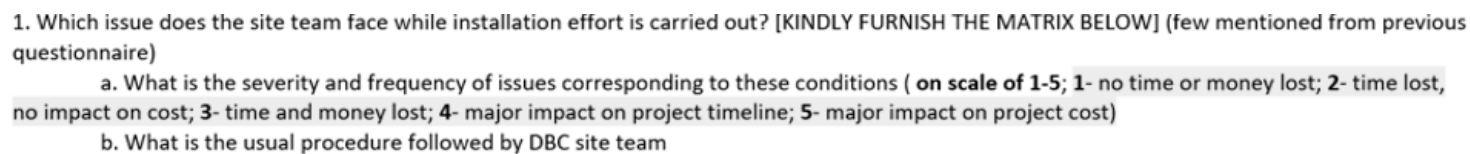

\begin{tabular}{|l|l|l|l|}
\hline Condition & $\begin{array}{l}\text { Severity (impact on } \\
\text { cost and time for } \\
\text { project) }\end{array}$ & $\begin{array}{l}\text { Frequency (how often } \\
\text { does it happen) }\end{array}$ & $\begin{array}{l}\text { Standard procedure } \\
\text { followed }\end{array}$ \\
\hline $\begin{array}{l}\text { Wall panel clashes with } \\
\text { beam/column }\end{array}$ & 2 & 1 & $\begin{array}{l}\text { Add pocket for beam, } \\
\text { lower pocket for beam }\end{array}$ \\
\hline MEP clash & 2 & 1 & $\begin{array}{l}\text { Add/most studs to } \\
\text { accommodate MEP. } \\
\text { Alternate is for MEP to } \\
\text { move, requires re- } \\
\text { coordination. }\end{array}$ \\
\hline Not enough height clearance & 3 & 1 & $\begin{array}{l}\text { Cut top of wall and add } \\
\text { slotted track. }\end{array}$ \\
\hline
\end{tabular}

\section{REFERENCES}

Arditi, D., and Gunaydin, H. M. (1997). "Total quality management in the construction process.” International Journal of Project Management, 15(4), 235-243.

Cho, S., and Fischer, M. (2010). "Real-Time Supply Chain Management Using Virtual Design and Construction." Proceedings for the 18th Annual Conference of the International Group for Lean Construction, (July), 212-221.

Filho, J. B. P. D., Angelim, B. M., Guedes, J. P., Silveira, S. S., and Neto, J. de P. B. (2016). "Constructability Analysis of Architecture-Structure Interface Based on BIM." 24th Annual Conference of the International Group for Lean Construction, 73-82.

Gerber, D. J., Becerik-Gerber, B., and Kunz, A. (2010). "Building Information Modeling and Lean Construction: Technology, Methodology and Advances From Practice." 18th Annual Conference, 1-11.

Gleason, D. (2013). "Laser Scanning for an Integrated BIM." Lake Constance 5D Conference.

Murphy, M., McGovern, E., and Pavia, S. (2009). Historic building information modelling (HBIM). Structural Survey.

Tillmann, P., Viana, D., Sargent, Z., and Tommelein, I. (2015). "Bim and Lean in the Design - Production Interface of Eto Components in Complex Projects." Iglc, 331340.

Vishal, E., Waje, V., and Patil, E. V. (2015). "Cost of poor Quality in Construction." IOSR Journal of Mechanical and Civil Engineering, 2278-1684. 